УДК 34.09

\title{
П.В. Лушников
}

\section{ПРОБЕЛЫ В ПРАВЕ И СПОСОБЫ ИХ ВОСПОЛНЕНИЯ}

В статье рассматриваются вопросы пробельности права, констатируется, что в настоящее время проблема пробелов обусловлена развитием общественных отношений. Определены негативные последствия пробелов и причины их появления. Рассматривается несколько классификаций пробелов, которые сделаны в науке. Делается вывод о том, что преднамеренное создание пробелов субъектами правотворчества может быть коррупциогенным фактором. Подробно анализируется классификация пробелов в зависимости от истинности (реальные и мнимые). Мнимыми пробелы могут возникать как у адресатов, так и у адресантов правовых посланий. В первом случае у адресатов, в силу отсутствия необходимых знаний, может возникать ложное представление об отсутствии правового регулирования. При втором варианте высказывается согласие с научной позицией о том, что адресаты могут, в силу субъективных причин, пытаться урегулировать пробелы в праве, которых в действительности не существует, тем самым порождая излишнюю юридизацию либо реальные пробелы. В статье рассматриваются варианты восполнения пробелов в праве, предложенные в науке. Далее предлагается применять к данной проблематике положения герменевтики. Обосновывается возможность применения герменевтической методологии для устранения пробелов. Делается вывод о том, что в качестве меры по противодействию пробельности законов может быть использовано предварительное моделирование коммуникативных процессов в ходе правотворчества. Высказывается предложение о необходимости ограничения «произвола читателя» в процессе применения аналогии права и закона, а также в процессе формирования правового прецедента.

Ключевые слова: пробелы в праве, классификация пробелов в праве, способы устранения пробелов, толкование права, способы толкования, правотворчество, законодательная техника, аналогия права, аналогия закона, правовой прецедент, правоприменительная техника.

DOI: $10.35634 / 2412-9593-2020-30-3-396-405$

Пробельность права и закона является одной из проблем правотворчества в любой стране. Проблема пробельности в праве не является новой для правовой науки. В момент становления современного российского государства данная проблема была во многом связана с зарождением новых общественных отношений в экономике, политике и т. д. В настоящее время она обусловлена развитием общественных отношений, в том числе появлением новых технологий.

В трудах ученых-правоведов достаточно детально определены негативные последствия пробелов в праве. Они указывают на то, что пробельность нарушает единство правового пространства, снижает качество правового воздействия. Пробельные правовые нормы не способны как следует выполнять регулятивную функцию, из-за них снижается эффективность правовой системы в целом. Роль закона в обществе девальвируется, законодательное регулирование подменяется толкованием, часто некомпетентным, усиливается произвол исполнителей, теряется авторитет закона. Некачественно написанное законодательство не используется и захламляет правовое пространство, Создает нестабильность и неопределенность в правовом регулировании ${ }^{1}$.

Ж.И. Овсепян отмечает, что в общей теории права под пробелом в праве понимается «полное или частичное отсутствие правового регулирования конкретного вида общественных отношений в определенной сфере», которое, в принципе, возможно регулировать нормами права и «объективно требует» правового регулирования ${ }^{2}$.

Е.В. Васьковский ${ }^{3}$ полагал, что пробел в действующем праве имеется тогда, когда для какойлибо категории случаев или 1) вовсе нет нормы, или 2) существует норма, но совершенно темная и

\footnotetext{
${ }^{1}$ См.: Прокофьев Г.С., Чигидин Б.В. Технология подготовки законопроектов // Законодательный процесс. Понятие. Институты. Стадии: науч.-практ. пособие. М.: Юриспруденция, 2000. С 115-116; Тихомиров Ю.А. Юридическое проектирование: критерии и ошибки // Журнал российского права. 2008. № 2; Лапина И.А. Дефекты законодательных актов субъектов Российской Федерации // Конституционное и муниципальное право. 2008. № 21. С. 16-17.

${ }^{2}$ Овсепян Ж.И. Пробелы и дефекты как категории конституционного права // Конституционное и муниципальное право. 2007. № 15. С. 10-11.

${ }^{3}$ Васьковский Е. В. Руководство к толкованию и применению законов. М., 1997. С. 96. Цит. по: Петров А.А., Тихонравов Е.Ю. Пробелы и коллизии в праве: учеб. и науч.-практ. пособие. М., 2017. С. 13.
} 
непонятная, или 3) существует несколько норм, находящихся между собой в непримиримом противоречии, или 4) установлена норма, страдающая неполнотой.

Правоведы выделяют несколько причин возникновения пробелов в праве. Пробел может возникнуть по объективным причинам после издания нормативно-правового акта в результате развития общественных отношений в соответствующей сфере, появления новых отношений, не предусмотренных этим правовым актом ${ }^{4}$. Субъекту правотворчества сложно предусмотреть все возможные варианты развития и изменений общественной жизни. Иногда такие изменения происходят стремительно. В такой ситуации законодатель объективно не поспевает за развитием общественных отношений 5 .

В качестве объективной причины возникновения пробелов также называется многообразие общественных отношений и моделей их развития и реализации. Полагаем, что данное обстоятельство можно условно назвать объективным. При достаточном изучении общественных отношений, выбранных для регулирования, можно выявить все текущие жизненные ситуации и их модели развития и варианты протекания, а также сделать предположения и спрогнозировать большинство отклонений от общих правил регулирования, то есть определить основные нарушения и редко встречающиеся ситуации.

Особо указывается на то, что пробелы могут возникать из-за недостатков в работе правотворческого органа как дефекты законодательной политики и законодательной техники. В частности, называют следующие дефекты: правовой идеализм, ситуационный характер принятия решений, точечное решение проблем, политика «латания дыр», сомнительная политическая целесообразность ${ }^{6}$; непринятие необходимого нормативно-правового акта либо неправомерное затягивание со сроками его принятия ${ }^{7}$; поспешность в разработке и недостаточное обоснование необходимости принятия ${ }^{8}$; недостаточный охват всех возможных жизненных ситуаций (всех аспектов правоотношений), которые регулируются нормативным актом' ${ }^{9}$ бессистемность и несогласованность между различными нормами одного или нескольких нормативно-правовых актов ${ }^{10}$; неопределенность механизма реализации нормативного акта ${ }^{11}$.

В научной литературе выделяют несколько классификаций пробелов:

- в зависимости от момента возникновения - первоначальные (недосмотр законодателя) и последующие. Первоначальные пробелы возникают, когда необходимость в правовом регулировании существует уже в момент прохождения законопроекта, последующие возникают в результате развития общественных отношений ${ }^{12}$;

- в зависимости от полноты правового регулирования - полные, частичные, то есть в виде полного отсутствия какого-либо регулирования вопроса и в виде неполноты имеющегося регулирования $^{13}$. Неполнота существующего правового регулирования характеризуется разной степенью и объемом охвата: пробелы в позитивном праве, пробелы в нормативно-правовом регулировании, пробелы в законодательстве, пробелы в законе. Такого рода пробелы могут проявляться в отсутствие нормативного правового акта, регулирующего соответствующую сферу отношений; в отсутствие в нормативном правовом акте норм, регламентирующих часть правоотношения; в неверных способах ссылок как в тексте самого акта, так и отсылок к другим актам ${ }^{14}$;

\footnotetext{
${ }^{4}$ Морозова Л.А. Теория государства и права. М.: Юристь, 2002. С. 288.; Тихомирова Л.В., Тихомиров М.Ю. Юридическая энциклопедия. М., 2002. С. 707.

${ }^{5}$ Морозова Л.А. Теория государства и права. М.: Юристъ, 2002. С. 288.

${ }^{6}$ См.: Зайцева Е.С., Козловский П.В. Понятие «мнимые пробелы в праве» и роль мнимых пробелов в механизме правового регулирования // Современное право. 2015. № 7 // СПС «КонсультантПлюс».

7 Тихомиров Ю.А. Проблемы развития законодательства субъектов Российской Федерации // Конституционное и муниципальное право. 2009. № 3. С. 4.

${ }^{8}$ См.: Тихомиров Ю.А. Юридическое проектирование: критерии и ошибки // Журнал российского права. 2008. № 2 // СПС «КонсультантПлюс».

${ }^{9}$ См.: Морозова Л.А. Теория государство и права. М.: Юристъ, 2002. С. 288.; Тихомирова Л.В., Тихомиров М.Ю. Юридическая энциклопедия. М., 2002. С. 707.

10 Щепачев В.А. Совершенствование правовой работы в представительном органе местного самоуправлении // Конституционное и муниципальное право. 2008. № 21. С. 29.

11 Лапина И.А. Дефекты законодательных актов субъектов Российской Федерации // Конституционное и муниципальное право. 2008. № 21. С. 15.

12 Лазарев В.В., Липень С.В. Теория государства и права: учебник. М., 2002. С. 355.

13 Лазарев В.В., Липень С.В. Указ. соч. С. 370.

14 Тихомиров Ю.А. Юридическое проектирование: критерии и ошибки // Журнал российского права. 2008 . № 2 // СПС «КонсультантПлюс».
} 
- в зависимости от наличия или отсутствия умысла правотворческого субъекта - преднамеренные (умышленные) и непреднамеренные пробелы. О преднамеренных пробелах «говорят, например, там, где законодатель сознательно оставил вопрос открытым с целью предоставить его решение течению времени или отдавая его решение на усмотрение практических органов. Сюда же относят иногда случаи, когда закон содержит ссылки на какие-либо факторы (добрые нравы, практику и т.п.), а правоприменителю предоставляется право конкретизировать абстрактные понятия, употребленные в законе» ${ }^{15}$. Со своей стороны добавим, что умышленные пробелы могут закладываться в нормативно-правовой акт не только исходя из указанных выше целей, но также с целью скрыть часть информации от адресатов. Такой пробел может быть коррупциогенным фактором ${ }^{16}$;

- в зависимости от наличия либо отсутствия умысла законодателя различают пробелы в праве, имеющие объективную и субъективную природу. Объективные по природе пробелы в праве возникают в случаях, когда законодатель не готов к принятию того или иного закона. Законодательный орган раздирают политические страсти, столкновение интересов между социальными группами, политическими партиями, палатами представителей. Общественные отношения обладают такой новизной и степенью сложности, что непонятно, как и с помощью каких правовых средств их надо регулировать. Пробелы в праве, имеющие субъективную природу, выражаются как несовершенство законодательства, отсутствие надлежащей законодательной техники и т. п. ${ }^{17}$

Интересной является критерий классификации пробелов в зависимости от степени истинности. Л.А. Морозова выделяет в этой категории пробелы реальные и мнимые. Она обосновывает это следующим образом: «Под мнимыми пробелами понимается преднамеренное молчание законодателя, т.е. когда он сознательно оставляет вопрос открытым, предлагая передать его решение на усмотрение правоприменителя, или законодатель сознательно выводит данные общественные отношения за сферу правового регулирования. Такое действие законодателя именуют квалифицированным молчанием». Подлинные (реальные) пробелы свидетельствуют об ущербности законодательства и об определенных недостатках правовой системы ${ }^{18}$.

По сути Л.А. Морозова под мнимыми пробелами понимает преднамеренные пробелы (Лазарев В.В., Липень С.В.), а под реальными - пробелы, возникшие по субъективным причинам, непреднамеренные (Венгеров А.Б. и Лазарев В.В., Липень С.В.).

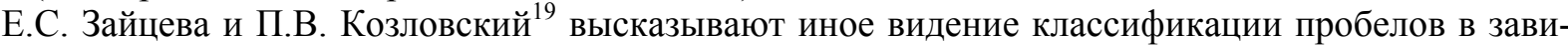
симости от истинности. Они отмечают, что, как правило, в центре внимания исследователей находятся лишь реальные пробелы, то есть имеющие место в действительности, когда отсутствует необходимое правовое регулирование общественных отношений. Такое понимание фактически совпадает с определением пробела как такового. Мнимые же пробелы сложно выявить, так как они имеют свое отражение в сознании субъектов правотворчества и на первый взгляд не оказывают влияния на функционирование механизма правового регулирования. В нормативных правовых актах отражаются не только истинные представления законодателей, но и их заблуждения и иллюзии о необходимости урегулирования тех или иных общественных отношений. В результате чего неосознанные, созданные искусственно, надуманные пробелы превращаются в правовые нормы, потребность в которых не обусловлена объективным развитием общественных отношений.

Деятельность законодателя по устранению такого рода пробелов может приводить в результате к излишней юридизации общественных отношений либо, наоборот, к возникновению реальных пробелов.

Появление мнимых пробелов и их материализация в действующем законодательстве обусловлены двумя причинами:

- во-первых, правовым идеализмом как формой деформации правосознания законодателя. Это выражается в ограниченности знаний авторов нормативно-правовых актов о закономерностях развития правовой материи и юридической практики, непонимании ими объема правового регулирования,

\footnotetext{
15 Лазарев В.В., Липень С.В. Теория государства и права: учебник. М.: СПАРК, 2002 С. 370.

${ }^{16}$ Постановление Правительства РФ от 26.02.2010 № 96 «Об антикоррупционной экспертизе нормативных правовых актов и проектов нормативных правовых актов» (вместе с «Правилами проведения антикоррупционной экспертизы нормативных правовых актов и проектов нормативных правовых актов», «Методикой проведения антикоррупционной экспертизы нормативных правовых актов и проектов нормативных правовых актов»).

${ }^{17}$ Венгеров А.Б. Теория государство и права: учебник. 3-е изд. М.: Юриспруденция, 2000. С. 436-437.

${ }^{18}$ Морозова Л.А. Теория государство и права. М.: Юристъ, 2002. С. 288.

19 Зайцева Е.С., Козловский П.В. Понятие «мнимые пробелы в праве» и роль мнимых пробелов в механизме правового регулирования // Современное право. 2015. № 7. С. 33-37.
} 
в существовании в их сознании завышенных ожиданий относительно возможностей механизма правового регулирования;

- во-вторых, отсутствием системной правотворческой политики, направленной на получение адекватной оценки развития общественных отношений и на понимание возможностей использования правовых средств для их регулирования.

Исторически одним из первых способов восполнения пробелов был «порядок докладов». Говоря об этом способе К.И. Малышев ${ }^{20}$ указывал, что в ряде государств каждый из судебных органов, встретившись с пробелом в праве, был обязан приостановить решение дела и выйти с докладом в законодательные учреждения о разъяснении или дополнении законов. По поводу этих докладов издавались пояснительные законы, рескрипты и тому подобные произведения аутентического толкования, и уже в соответствии с этими правилами суды разрешали дела. В дальнейшем от данного порядка отказались ввиду его громоздкости и трудозатратности. Вместо него во многих государствах распространение получили другие способы и приемы обращения с пробелами в праве, которые предполагают возможность восполнения пробелов вне законотворческого процесса и направлены на преодоление пробела в праве в конкретном случае ${ }^{21}$. Согласно распространенным общетеоретическим представлениям, такими способами преодоления пробелов считаются «аналогия закона и аналогия права» ${ }^{22}$.

Тем не менее правотворчество определяется учеными как основной способ восполнения пробелов. Представляется, что субъекты, выявившие пробел, могут апеллировать к законодателю (в широком смысле этого слова) о восполнении юридической лакуны ${ }^{23}$. Помимо законотворческого пути восполнения пробелов выделяют также и подзаконное нормотворчество. Однако такая деятельность по сути является вторжением в компетенцию законодателя, что признается недопустимым.

Так как правотворчество - относительно долгий путь, то существенная роль в деле восполнения пробелов отводиться правоприменителям. Это особый вид деятельности, так как преодоление юридических лакун требует создания предписаний, которые нельзя назвать результатом ни правоприменения, ни правотворчества ${ }^{24}$. В российской науке рассматриваются два основных способа восполнения пробелов: аналогия закона и аналогия права. Применяя аналогию, орган, восполняющий пробел, должен выработать представление о правиле, рассчитанном на регламентацию однотипных с пробельным случаем ситуаций. На основе такой неправовой нормы только и может быть создано конкретное предписание для разрешаемого дела, преодолевающее юридическую лакуну ${ }^{25}$. Обращение к этим методам подразумевает утаивание формулирования и реализации правовосполнительного предписания под видом применения действующей правовой нормы. В качестве последней при использовании аналогии закона выступает юридическое правило, непосредственно регулирующее конкретные жизненные ситуации, при аналогии права - юридический принцип ${ }^{26}$. Такие принципы заимствуются из имеющихся в системе права.

В теории также указывается, что восполнение пробелов в законодательстве может осуществляться путем обращения к иным, нежели нормативные акты, источникам права - правовой прецедент, обычай делового оборота, нормативный договор, правовая доктрина. Кроме того, в качестве способов восполнения пробелов в теории также рассматриваются и другие приемы: расширительное толкование правовых норм; восполнение юридических лакун посредством вынесения судом решения согласно правилам, которые он установил бы, будучи законодателем; преодоление пробелов в праве путем вынесения судом решения, не подкрепляемого юридической аргументацией; восполнение юридических лакун с помощью естественного права ${ }^{27}$. На наш взгляд, вышеперечисленные приемы являются разновидностями судебного прецедента.

\footnotetext{
${ }^{20}$ Малышев К. И. Курс общего гражданского права России. СПб., 1878. Т. І. С. 283. Цит. по: Петров А.А., Тихонравов Е.Ю. Пробелы и коллизии в праве: учеб. и науч.-практ. пособие. М., 2017. С. 16.

${ }^{21}$ Петров А.А., Тихонравов Е.Ю. Указ.соч. С. 18.

${ }^{22}$ Овсепян Ж.И. Пробелы и дефекты как категории конституционного права // Конституционное и муниципальное право. 2007. № 15. С. 10-11.

${ }^{23}$ Прокофьев Г.С., Чигидин Б.В. Технология подготовки законопроектов // Законодательный процесс. Понятие. Институты. Стадии: науч.-практ. пособие. М.: Юриспруденция, 2000.

${ }^{24}$ Петров А.А., Тихонравов Е.Ю. Пробелы и коллизии в праве...С. 18

${ }^{25}$ Там же.

26 Дробышевский С.А., Тихонравов Е.Ю. Способы восполнения пробелов в праве. М., 2014. С. 83-122. Цит. по: Петров А.А., Тихонравов Е.Ю. Пробелы и коллизии в праве: учеб. и науч.-практ. пособие. М., 2017. С. 21.

${ }^{27}$ См.: Петров А.А., Тихонравов Е.Ю. Пробелы и коллизии в праве: учеб. и науч.-практ. пособие. М., 2017. С. 25-33.
} 
В последние годы в юридической науке активно проявляется интерес к герменевтическим знаниям. Герменевтика - это научно-философское направление, разрабатывающее вопросы понимания. Эта категория в герменевтике рассматривается как процесс, происходящий в социальных коммуникациях, направленный на нахождение и постижение смыслов. Понимание рассматривается и как состояние, достигаемое участниками социальных коммуникаций, на вхождение, в которое направлена их коммуникативная деятельность. Герменевты ${ }^{28}$ указывают, что окружающий мир и его явления воспринимаются человеком как набор смыслов, выраженных в знаковой форме (т. е. своего рода текст). В этом аспекте понимание - есть состояние нахождения в мире, результат мыслительной деятельности, направленной на осознание, усвоение определенных текстов.

Процесс понимания в герменевтике основывается на ряде принципов (основополагающих правил $)^{29}$, к числу основных относят:

- принц̧ип герменевтического круга - понимание всего теста возможно, если поняты его части, и наоборот;

- принц̧ип диалогического понимания - понимание достигается в ходе диалога автора и читателя посредством текста;

- принции цุелеполагания - осознание коммуникаторами цели коммуникации;

- принции контекстного понимания - понимание текста осуществляется через его контекст;

- принцип конгениальности - соразмерность потенциалов автора и читателя;

- принцип продуктивного понимания - переосмысливание читателем авторского текста и «дописывание» его с учетом конкретной коммуникативной ситуации;

- принцип знания и понимания автора текста - необходимость понять автора лучше, чем он сам себя понимает.

Изучение правовой герменевтики как прикладного научного направления натолкнуло нас на мысль о том, что проблему пробелов в праве можно рассмотреть с позиций правовой герменевтики. На наш взгляд, такой подход позволит взглянуть на проблему пробелов с иной стороны и расширить правовые знания об их природе и способах их преодоления.

С точки зрения герменевтики пробел - это отсутствие смысла и как результат - состояние непонимания. Как было указано правоведами, отсутствие смысла возникает не умышлено, но может быть и преднамеренным. В любом случае в тексте права (в широком смысле) возникает «темное место» (смысловой разрыв), в результате чего участники коммуникации утрачивают понимание. Для преодоления этого требуется применение методологии понимания.

С учетом рассмотренных выше точек зрения правоведов на причины возникновения пробелов в праве и их классификацию мы сделали вывод о том, что с точки зрения герменевтики пробелы в праве возникают или вследствие непонимания, или являются причиной непонимания.

В первом случае такой пробел является дефектом коммуникации, во втором - дефектом правотворчества. Для каждого из участников коммуникации (адресанта-адресата) любая из этих ситуаций протекает по-своему и требует совершения своих определенных действий для ее преодоления.

\section{1. Пробелы в праве, возникшие вследствие непонимания}

1) Со стороны адресата. Если у адресата отсутствуют юридическое знание, навыки толкования норм права или сведения о факте, целях и об объеме правового регулирования, то он оказывается в ситуации непонимания, в некоторых случаях даже не зная об этом. При этом правовое регулирование в сфере, где возникло непонимание, фактически существует, но нормы права применяются только теми, кто знает об их существовании. Возникает состояние неосведомленности, ввиду чего читатели правовых посланий считают законодательство пробельным, то есть возникает мнимый пробел.

В связи с этим хотелось бы высказать свою точку зрения на классификацию пробелов в зависимости от степени истинности. Как было отмечено выше, Л.А. Морозова ${ }^{30}$ называет «мнимыми» те пробелы, которые сделаны законодателем специально. На наш взгляд, указанные пробелы более уместно называть преднамеренными или умышленными. Под «мнимым» же пробелом следует понимать ситуацию, когда читатель не знает о существовании нормативно-правового акта в необходимой ему

\footnotetext{
${ }^{28}$ Гадамер Х.Г. Истина и метод. М., 1988; Кузнецов В.Г. Герменевтика и гуманитарное познание. М.: Изд-во МГУ, 1991.

${ }^{29}$ Там же.

${ }^{30}$ Морозова Л.А. Теория государство и права. М.: Юристъ, 2002. С. 288.
} 
сфере либо не может понять текст нормативно-правовых актов в силу отсутствия навыков правового толкования. В результате чего у него возникает не соответствующее действительности представление об отсутствии правового регулирования (нужной нормы или нужного нормативно-правового акта).

Неподготовленные участники правоотношений зачастую не обладают навыками толкования и не всегда могут увидеть связи между нормативными актами, понять их контекст. В настоящее время отсутствуют доступное официальное толкование норм права и разъяснение системы норм, осуществляющих правовое регулирование. В такой ситуации адресату необходимо обращаться к квалифицированному посреднику, который может проинформировать о существовании нормы права либо осуществить разъяснение ее смысла.

2) Со стороны адресанта. В такой ситуации для адресанта правового послания пробела в праве нет, так как им приняты необходимые акты и правовое регулирование осуществляется, а в силу положений Конституции РФ на адресатов возложена обязанность знать законодательство. Однако вследствие большого объема законодательства поиск необходимого законодательного акта и ознакомление с ним является делом затруднительным, в ряде случаев даже для профессионалов. Отсюда возникает дефект коммуникации между субъектом правотворчества и субъектами реализации права адресанту кажется, что его правовые послания дошли до адресатов, а адресаты даже не знают о том, что правовые послания существуют. На существование такого мнимого пробела и на дефект коммуникации можно закрывать глаза, если у адресанта правового послания отсутствует желание, чтобы принятый им нормативный акт был реализован. В противном случае, как отмечает, Ю.А. Тихомиров $^{31}$, если гражданам недостаточно разъясняется смысл новых законов, это приводит к снижению эффективности их восприятия и дальнейшей реализации.

Полагаем, что вопрос о преодолении мнимых пробелов является насущным, так как это может привести к неисполнению или неточному исполнению правовых предписаний, произвольному толкованию норм права и т.д. Это может в конечном итоге приводить к увеличению управленческих расходов.

Возникновение пробела вследствие непонимания по сути и есть отсутствие реализации ряда герменевтических принципов: конгениальности между автором и читателем, целеполагания, диалогичности, контекстуальности понимания. Это приводит к невозможности для читателя выйти из герменевтического круга, так как он не видит ни частного, ни целого смыслов, отсюда не видит или не может выстроить смысл всего текста. В данном случае адресант может помочь адресату реализовать понимание в герменевтическом круге через определение контекста, в котором читатель может найти все необходимые для него общие и частные смыслы для воссоздания единого смысла. Способами преодоления таких пробелов можно считать деятельность адресантов по созданию адресатам условий для понимания правовых посланий и правовое просвещение, разъяснение целей и механизма правового регулирования, раскрытие системы законодательства, разъяснение правоприменительной практики. Полагаем, что одним из существенных механизмов устранения мнимых пробелов может быть официальное аутентичное толкование норм права.

\section{2. Пробел в праве, являющийся причиной непонимания}

1) Со стороны адресанта. Причиной пробельности может быть недостаточная познавательная деятельность законодателя. Выбраны ненадлежащие методы познания социальной реальности либо недостаточно полно и точно исследована историко-культурная ситуация в обществе, не изучены социальные коммуникации и их участники. Отсюда одной из причин пробелов в законодательстве может быть непонимание адресантом сущности общественных процессов (социальных коммуникаций), требующих регулирования. Это может приводить к неверному правовому регулированию: к выбору необоснованной цели, к использованию неадекватных методов и к возникновению неполного регулирования.

Такое представление о пробелах отчасти соотноситься с приведенной выше позицией Е.С. Зайцевой и П.В. Козловского ${ }^{32}$ относительно «мнимых» пробелов. Позиция указанных исследователей о том, что законодатель тоже может выдумать ошибочные потребности в правовом регулировании и тем самым породить пробелы, подтверждается положениями герменевтики.

\footnotetext{
${ }^{31}$ Тихомиров Ю.А. Юридическое проектирование: критерии и ошибки // Журнал российского права. 2008. № 2 // СПС «КонсультантПлюс».

32 Зайцева Е.С., Козловский П.В. Понятие «мнимые пробелы в праве» и роль мнимых пробелов в механизме правового регулирования // Современное право. 2015. № 7 // СПС «КонсультантПлюс».
} 
В коммуникации роли автора и читателя отчасти условны и могут переходить одна в другую. В герменевтике общество может рассматриваться как смысловое пространство, состоящее из совокупности текстов, то есть социум - это некоторая текстуальная реальность. Следовательно, законодатель, познавая требующие правового регулирования общественные отношения, становиться читателем, который познает общество через тексты (статистика, обращения избирателей, отчеты о деятельности органов власти и много другое). Законодатель как читатель может оказываться в состоянии непонимания и предпринимать меры к его преодолению, в том числе и ошибочные, не приводящие к результату. Соответственно, совершая дальнейшее неадекватное коммуникативное взаимодействие с адресатами, он порождает у них состояние непонимания.

Традиционно герменевтика и ее методология применяются в праве в сфере толкования, то есть со стороны читателя. В последнее время в правовой науке высказываются мнения, что герменевтические знания можно использовать и в правотворчестве ${ }^{33}$. На наш взгляд, герменевтика позволяет посмотреть на процесс понимания не только со стороны читателя, но и со стороны автора. Поэтому мы поддерживаем указанные мнения.

В герменевтическом аспекте правотворчество представляет собой взаимодействие между адресантом-автором (законодателем) и адресатом-читателем (субъектом, реализующими право). В правовой коммуникативной паре взаимодействие направлено на передачу-получение правовой информации о целях, способах и правилах поведения в обществе. Соответственно, задачами адресанта являются инициирование коммуникации, качественное формулирование правового послания, передача правового послания адресату, при необходимости разъяснение своего послания, мотивирование адресата на следования нормам права. Задачами адресата являются получение правового послания, ознакомление с ним и осуществление процедуры для его понимания, реализация полученного правового предписания.

Мы думаем, что можно также выделить исходную задачу адресанта, предшествующую инициированию коммуникации, - изучение коммуникативного пространства и адресатов, находящихся в нем, видов и методов коммуникации, происходящих в обществе. Это пространство называется «герменевтическое сообщество» и имеет соответствующий дискурс общения адресатов. Из вышесказанного можно сделать вывод, что пробелы могут также появляться вследствие непонимания адресатом правового послания особенностей герменевтического сообщества, в рамках которого осуществляется коммуникация. Следовательно, перед законодателем стоит первоначальная задача - изучение герменевтического сообщества и адресатов (их характеристик, имеющихся у них ресурсов, определение возможных алгоритмов их поведения). Исходя из этого при формировании правового послания адресант может создать коммуникативную схему правоотношения, которая позволит осуществлять правовое регулирование с учетом особенностей участников конкретных социальных коммуникаций и имеющихся между ними взаимосвязей.

Эти выводы привели нас к идее о том, что на стадии написания проекта нормативного акта необходимо осуществить герменевтическое моделирование социальной коммуникации, требующей правового регулирования. Коммуникативно-герменевтическая модель проектируемого правоотношения может показать ход и результаты воздействия нормативного акта на общественные отношения ${ }^{34}$. Такая модель может быть создана следующим образом:

а) описание существующих социально-правовых коммуникаций;

б) прогнозирование изменения коммуникативной реальности после принятия нормативного правового акта;

в) разработка нормативного правового акта и определение путей и методов его реализации с учетом полученных данных.

Это даст возможность выявлять максимальное число коммуникационных связей, соответственно, выявит максимальное число жизненных ситуаций и вариантов их развития и протекания. В свою очередь это уменьшит количество пробелов в праве, вызванных тем, что часть этих ситуаций осталась не урегулирована вновь принятым нормативно-правовым актом.

\footnotetext{
${ }^{33}$ См.: Гермашев А.Н. Юридическая герменевтика как теория о способах изложения воли в юридическом тексте и способах ее толкования: дис. канд. юрид. наук. М., 2010; Малинова И. П. Философия правотворчества. Екатеринбург: УрГЮА, 1996.

${ }^{34}$ Идея моделирования правоотношений в ходе правотворчества в науке уже высказывалась (например, криминологические модели). Мы считаем, что предлагаемая модель в сочетании с другими может повысить качество правотворческой деятельности.
} 
2) Со стороны адресата. В такой ситуации адресат встречается с реальным пробелом, который он видит и понимает, при этом может осознавать, что адресант допустил пробел по объективным или субъективным причинам. Для решения своих коммуникативных задач адресат может либо обратиться к адресанту с предложение разъяснить или уточнить свое послание, либо попробовать самостоятельно преодолеть лакуну. Первый путь решения задачи предполагает реализацию принципа диалогического понимания, когда читатель выявляет в тексте вопрос, поставленный автором, а затем ищет ответ на него в тексте. Не находя ответа, обращается к другим произведениям автора, к произведениям об авторе, к смежным источникам либо обращается непосредственно к автору, если есть такая возможность. Такой путь является длительным и трудозатратным. В ситуации, когда адресант правового послания сам не осознает созданный пробел, обращение адресата может быть бесполезным. Другой путь предполагает преодоление непонимания через использование герменевтического принципа продуктивного понимания.

Выше мы уже упомянули об относительности ролей участников коммуникации, указав, что автор может при подготовке нормативного акта оказаться в роли читателя. Отметим, что герменевтами предполагается и обратная ситуация, когда читатель может оказаться в роли автора (соавтора).

Процесс понимания (преодоления непонимания) предполагает совершение читателем активных действий по поиску и интерпретации смыслов. Результатом такой деятельности может быть создание интерпретационного текста (объясняющего и делающего понятным исходный текст). При этом интерпретатор может дописывать и домысливать текст, становясь соавтором.

В правовой науке принцип продуктивного понимания нашел свое отражение в концепции аналогии права и закона, а также в концепции правовых прецедентов. Предполагается, что квалифицированный читатель правового послания получает возможность стать соавтором текста нормативного акта и осуществлять смыслообразование наравне с авторами: придавать новые смыслы, расширять контекст, изменять или дополнять существующие смыслы.

Рассматривая такую ситуацию с позиции юридической герменевтики, Д.А. Гаврилов ${ }^{35}$ отмечает следующее. Нормативная теория правопонимания «основывается на идеологии "умного" законодателя, который вездесущ, постоянно следит за изменениями в общественной жизни и своевременно, адекватно совершенствует действующее законодательство. Для сегодняшней практики работы российских правотворческих органов это скорее желаемый результат, чем отражение реального положения вещей». На практике это означает, что «если законодатель правильно и адекватно понял истинную социальную потребность правового регулирования типичных ситуаций, то нахождение "дела" означает одновременно познание подлинной воли законодателя, и в итоге уяснение смысла созданной им нормы права. Однако в тех случаях, когда законодатель неправильно, частично, или, образно говоря, "плохо" воспринял реальные общественные нужды, нормативистская схема понимания начинает давать "сбои"». У юристов возникает вопрос: что делать, когда закон «плох», а справедливость и практика в целом требуют дать ответ на возникший в жизни случай. Развивая тезис Г.Г. Гадамера о целевых установках понимания, Д.А. Гаврилов приходит к выводу «о наличии у интерпретатора права руководствоваться "делом", решить юридический казус разумно и справедливо, в соответствии с объективными интересами социума, а практически - внести в закон такую ясность и определённость, при которых он как бы "даёт" ответ на указанный казус и в состоянии будет предлагать ответ на аналогичные вопросы, задаваемые ему практикой» ${ }^{36}$.

В ситуации, когда жизнь бьет в колокола, в условиях длительного отсутствия надлежащей реакции законодателя на требования практики возникает также вопрос о степени возможного использования интерпретатором (правоприменителем) права понимать «дело» и порождать новый смысл в виде правила поведения для данного типа случаев как ответ на вопросы юридической практики. Эти рассуждения Д.А. Гаврилова вслед за Г.Г. Гадамером вывели его в сферу «чистого» прецедента. Но такая концепция понимания позволяет «оценивать законодателя как беспомощного "раба" обстоятельств, вынужденного поневоле апеллировать к правоприменяющим органам; законодатель становится на подчинённое место, а последние - выдвигаются вперёд» ${ }^{37}$.

\footnotetext{
${ }^{35}$ Гаврилов Д.А. Правоприменительное толкование: дис. ... канд. юрид. наук. Саратов, 2000. С. 27-28.

${ }^{36}$ Гаврилов Д.А. Указ.соч. С. 27-28.

${ }^{37}$ Там же.
} 
В свою очередь, рассуждая о праве правоприменителей создавать новые смыслы в процессе применения аналогии или в процессе формирования прецедента, мы хотим указать на существование герменевтической проблемы «произвола читателя». В герменевтике указывается, что произвольная интерпретация читателя может быть направлена против интересов автора, подменять его замыслы. Это значит, что читатель текста нормативного акта может интерпретировать его в угоду своим сиюминутным интересам, вопреки здравому смыслу и общему замыслу законодателя. Таким образом, свобода интерпретации читателя и возможность его соавторства могут иметь как положительный, так и отрицательный результат.

Восполнение пробелов в ситуации, когда этого требует практика в интересах людей и разрешения конкретного дела, является положительным. Однако современная концепция законодателя как непрофессионального представительного правотворческого органа, могущего состоять из непрофессионалов, предполагает ряд положительных аспектов: разработчики закона не имеют профессиональной деформации и тоннельного мышления, но имеют неограниченное время для разработки проекта нормативного акта, что позволяет им проработать его с разных позиций, изучить экспертные мнения, статистику и др. и согласовать разные социальные интересы. Правоприменитель по объективным и субъективным причинам органичен в сроках рассмотрения дела и возможностях разностороннего изучения и рассмотрения спорной ситуации. Поэтому ему сложно найти социальный консенсус и учесть в своем решении интересы наибольшего числа людей. Кроме того, правоприменитель может действовать исходя из своих ведомственных интересов, подрывая авторитет законотворческого органа. Ввиду возможности «произвола читателя» правового послания возникает вопрос о создании механизма или алгоритма поиска аналогии права или закона, который бы обеспечивал восполнение пробелов так, чтобы сохранить целостность правовой системы. В основу такого механизма может быть положено использование принципов диалогичности понимания, целеполагания, контекстного понимания, знания и понимания автора.

Подводя итог нашим рассуждениям, мы можем сделать следующие выводы. Мнимые пробелы в праве с точки зрения герменевтики имеют две стороны. С одной стороны - это мнимое непонимание нормативного регулирования субъектами реализации права, с другой стороны - это мнимое понимание необходимости правового регулирования субъектами правотворчества. Мы полагаем, что герменевтические знания могут быть использованы для предупреждения и устранения пробелов в праве. На наш взгляд, использование герменевтических принципов при проведении правотворческой политики позволит уменьшить количество пробелов в принимаемых правотворческих актах. Расширение использования герменевтической методологии в толковании права может позволить применять аналогию права и закона в рамках существующей правовой доктрины и правовой системы.

Справедливости ради отметим, что проблема пробелов в праве в настоящее время стала менее серьезной, нежели несколько лет назад. Это связано с тем, что устранены многие из пробелов, образовавшихся в первые годы становления современной правовой системы современной России. Тем не менее объем отраслевых публикаций по данной теме показывает, что данная ситуация в правовом регулировании возникает относительно часто.

Поступила в редакцию 22.02.2020

Лушников Павел Викторович, старший преподаватель кафедры теории и истории государства и права ФГБОУ ВО «Удмуртский государственный университет»

426034, Россия, г. Ижевск, ул. Университетская, 1 (корп. 4)

E-mail: ems@udm.ru

\title{
P.V. Lushnikov \\ GAPS IN THE LAW AND WAYS TO FILL THEM
}

\author{
DOI: $10.35634 / 2412-9593-2020-30-3-396-405$
}

The article deals with the issues of gaps in law, it is stated that at present the problem of gaps is caused by the development of public relations. The negative consequences of gaps and their causes are determined. Several classifications of gaps that are made in science are considered. It is concluded that the deliberate creation of gaps by the subjects of lawmaking can be a corruption-induced factor. The classification of gaps depending on the truth (real and imaginary) is 
analyzed in detail. It is concluded that under the imaginary spaces can occur, both the addressees and the addressees of legal messages. In the first case, the addressees due to lack of necessary knowledge may have a false idea about the lack of legal regulation. When considering the second option, there is agreement with the scientific position that the addressees may, for subjective reasons, try to resolve gaps in the law, which do not really exist, thereby giving rise to excessive legitimization or real gaps. The article considers the options of filling the gaps in the law proposed in science. Further, it is proposed to apply to this problem the provisions of hermeneutics. The possibility of applying hermeneutic methodology to eliminate gaps is substantiated. It is concluded that preliminary modeling of communicative processes in the course of law-making can be used as a measure to counteract the gap in laws. The author suggests the need to limit the "arbitrariness of the reader" in the process of applying the analogy of law and law, as well as in the process of forming a legal precedent.

Keywords: gaps in law, types of gaps in law, corruption, classification of gaps in law, ways to eliminate gaps, legal hermeneutics, methodology of legal hermeneutics, interpretation of law, hermeneutical principles, legal communication, participants of legal communication, lawmaking, analogy of law, analysis of law, legal precedent, legal modeling.

Lushnikov P.V., Senior lecturer of the Department of Theory and history of state and law Udmurt State University

Universitetskaya st., 1/4, Izhevsk, Russia, 426034

E-mail: ems@udm.ru 